\title{
PLANKTON COMPOSITION AND POTENTIAL OF CONTAMINATING ALIEN SPECIES VIA BALLAST WATER DISCHARGED IN COLOMBO HARBOR
}

\author{
S.C.D. Siyambalapitiya ${ }^{1}$, R.R.M.K.P. Ranatunga ${ }^{1}$, A.J.M. Gunasekara ${ }^{2}$ and N. \\ priyadarshana $^{2}$ \\ ${ }^{1}$ Department of Zoology, University of Sri Jayewardenepura, Sri Lanka \\ ${ }^{2}$ Marine Environmental Protection Authority, Sri Lanka
}

\begin{abstract}
Colombo harbor is one of the key harbors in south Asia due to its strategic location in the main east-west shipping route. Therefore, Colombo port and adjacent marine environment is under risk of introducing alien species through the discharge of ballast water. When new species introduced to a particular location, existing composition will be altered. The present study was to investigate existing plankton species composition in Colombo harbor and adjacent marine environment and also to study the potential of contaminating alien species via ballast water discharge. Species abundance and composition were investigated for all the samples obtained from inner harbor, entrance, north harbor and south harbor. Among the 64 plankton species recorded, fish eggs had the highest abundance in inner harbor $\left(1095\right.$ numbers $\left./ \mathrm{m}^{3}\right)$ and nauplii larvae had the highest abundance in all the three outer harbor sites (6782, 8562 and 4242 (numbers $/ \mathrm{m}^{3}$ ) respectively). Plankton abundance showed significant differences $(\mathrm{p}=0.001$ ) with respect to their location. Chlorophyll-a concentration showed a strong positive relationship $\left(\mathrm{r}^{2}=0.890\right)$ with total plankton abundance. Further, 26 new zooplankton and dinoflagellate species were also recorded from the inner harbor area that were not recorded in the literature. Among these there were two species found in ship's ballast water namely Microsetella sp and Prorocentrum sp.
\end{abstract}

Keywords: Ballast water, alien species, Colombo harbor, plankton

\section{INTRODUCTION}

Biological invasions in marine habitats represent a recognized worldwide threat to the integrity of native communities, to economy and even to human health (Streftaris \& Zenetos, 2006). Sometimes impacts are quick and dramatic but more often they are indirect and subtle and may escape notice for some time (Poorter, 2009). One result of increased ship transport is the unintentional introduction of organisms into new areas (Gross \& Gross, 1996). The introduction of exotic species in this way is especially likely if there are only small differences in temperature and salinities between the ports of origin and the final destination (Gross \& Gross, 1996). Poorter (2009) states that an estimated 7000 species are carried around the world in ballast water every day.

Sri Lanka's strategic location within close proximity to the east-west maritime route for international trade ensures minimum diversion time for ships arriving at the Sri Lankan ports (Central Bank Report, 2009). At present there are two harbor projects namely Colombo South harbor extension project and Hambanthota harbor project are carrying out to meet up the high demand and efficient cargo handling which alarm the threat of ballast water invasions. Sri Lanka has not signed for the International maritime organization (IMO) rules and regulations since there is a lack of baseline data on plankton species in the Colombo harbor. In order to formulate laws and regulations on ballast water exchange and monitoring, a very good database on plankton species composition in Colombo harbor is imperative. Ballast water organisms are transported in their planktonic phase, and may alter the species composition in harbor area. Objectives of the study were to gather baseline information on plankton species composition in Colombo harbor and adjacent marine environment, and thereby to find out the potential of contaminating alien species through ballast water discharge.

Proceedings of the 15 ${ }^{\text {th }}$ International Forestry and Environment Symposium, 26-27 November 2010.

Published by Department of Forestry and Environmental Science, University of Sri Jayewardenepura, Sri Lanka. 


\section{MATERIALS AND METHODS}

Two sampling areas were selected namely inner harbor (I) and outer harbor. Three sampling sites were randomly chosen in inner harbor (Jaya Container Terminal-7: 6 ${ }^{0} 57^{\prime} 05.44^{\prime \prime} \mathrm{N} 79^{0} 51^{\prime} 08.87^{\prime} \mathrm{E}$, Jaya Container Terminal coaster berth: $6^{0} 56{ }^{\prime} 31.24$ ”N $79^{\circ} 51^{\prime} 00.92$ "E, Dockyard: $6^{0} 57^{\prime} 15.52^{\prime \prime} \mathrm{N}$ $\left.79^{0} 51^{\prime} 13.56^{\prime \prime} \mathrm{E}\right)$. Another three sampling sites were chosen from outer harbor (south harbor(S): $6^{0}$ $55^{\prime} 56.97^{\prime \prime} \mathrm{N} 79^{0} 50^{\prime} 19.26^{\prime \prime} \mathrm{E}$, north harbor $(\mathrm{N}): 6^{0} 58^{\prime} 33.32^{\prime \prime} \mathrm{N} 79^{0} 51^{\prime} 46.9243$ ”'E, entrance of the harbor (E): $6^{0} 57^{\prime} 23.64$ 'N $79^{0} 50^{\prime} 43.52$ "E) by considering the current direction of harbor area (Figure 1). As per the Jayaweera (1999) cited by Fernando (2007) and LHI (2009) the current direction generally directed towards the north. If this is the case, it is impossible for the alien planktonic species to drift with the ballast water to occur at any part of the sea south to the Colombo port (Fernando, 2007). Three replicates were obtained from each site and monthly sampling was conducted between February and June 2010.

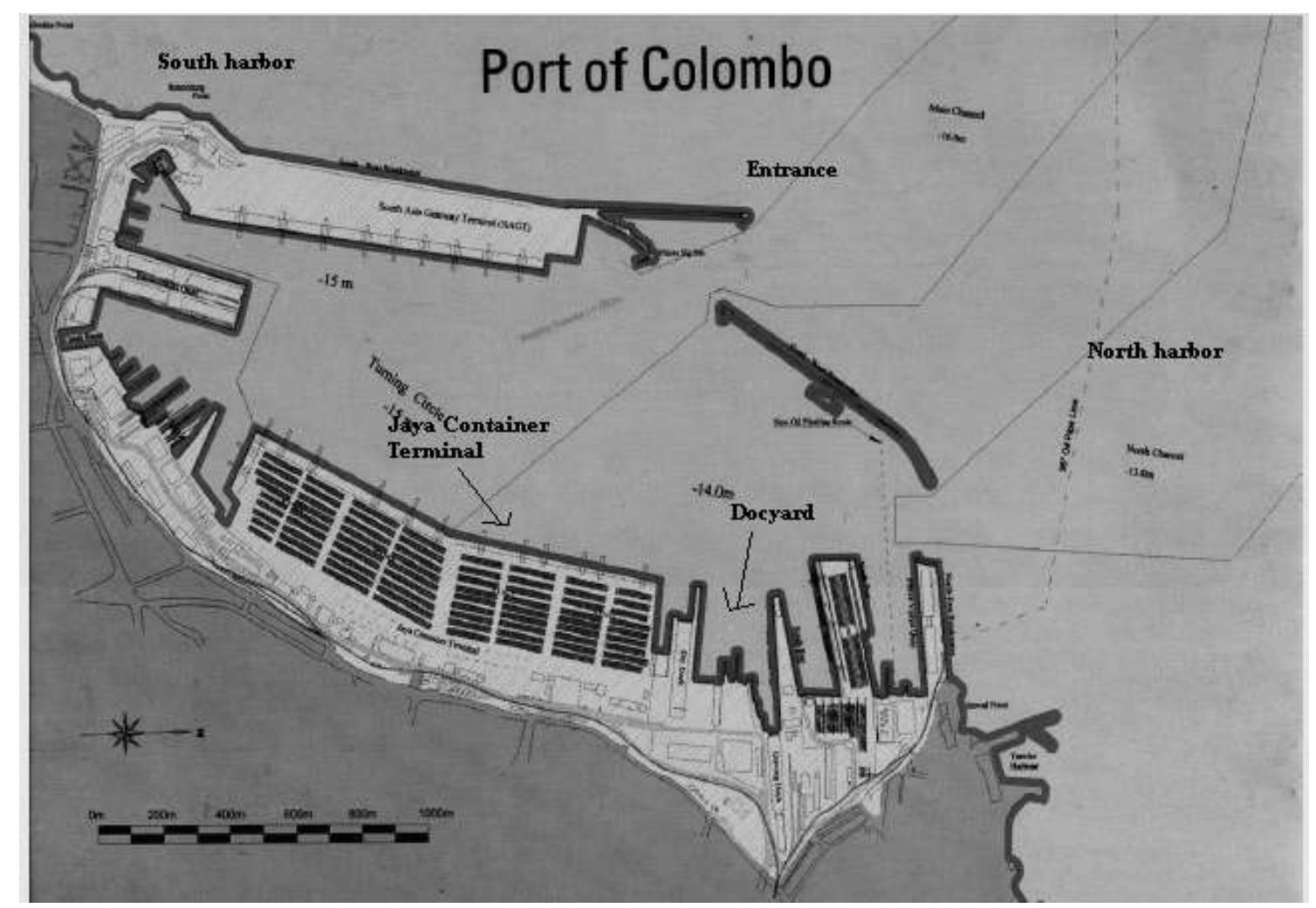

Figure 1: Map of the harbor showing sampling locations

Transverse plankton samples were collected from each sampling site by dragging the plankton net (mesh size $55 \mu \mathrm{m}$; Hydrobios kiel) approximately $150 \mathrm{~m}$ over the water surface to filter nearly $7.36 \mathrm{~m}^{3}$ of sea water. Plankton samples were preserved using lugol's solution $(1 \mathrm{ml}$ of lugol's solution per $100 \mathrm{ml}$ of the sample). Then zooplankton and phytoplankton in the samples were identified to the nearest taxonomic group using plankton identification guides (Botes,2003; Jayasiri,2009; Kasturirangan,1963; Perry, 2003). Images of plankton were observed by Microscope Image Projecti.082(I)7Bo3;.082(I)7Bo39(ov)11(e499)11()Malp)rßBßomBT1 001298.73 718.14)] [(Mi) 
SST was measured by a thermometer (Philips Harris), salinity was measured by a refractometer (ATAGO), conductivity was measured by the conductivity meter (wtw 330i) and $\mathrm{pH}$ was measured by using a $\mathrm{pH}$ meter (wtw 340).

Dissolved oxygen was measured using Winkler's method. Five-days BOD was also determined by Winkler's method. Orthophosphate concentration was determined using ammonium molybdate method (Grasshoff et al, 1999 and Robin \& Patra, 2009). Nitrate concentration was measured using sodium salicilate method and chlorophyll-a concentration using spectrophotometric method. Absorbance was measured with a Jenway 6305 UV/VIS Spectrophotometer.

Statistical analysis was conducted using MINITAB 14.0 version. Data were tested for normality by Anderson-Darling test $(\alpha=0.05)$ before using statistical analyses. One-way ANOVA was used with Tukey pair-wise comparison to investigate whether the total plankton abundance have a significant difference with respect to their location. Pearson correlation was used to see any relationship between total plankton abundance and physico-chemical parameters.

\section{RESULTS}

64 species of Zooplankton and Dinoflagellate species were recorded. Out of which 40 species found in inner harbor (I) and 34, 34 and 27 were found in entrance $(\mathrm{E})$, north harbor $(\mathrm{N})$ and south harbor (S) respectively.

In inner harbor, highest abundance $\left(1095\right.$ numbers $\left./ \mathrm{m}^{3}\right)$ was recorded for fish eggs while nauplii larvae had the highest abundance $\left(6757,8562\right.$ and $4242\left(\right.$ numbers $\left.\left./ \mathrm{m}^{3}\right)\right)$ in the entrance, north harbor and south harbor respectively. At $95 \%$ confidence interval total abundance of plankton showed significantly differences with location $(\mathrm{p}=0.001)$. Tukey's pair wise comparison showed that total plankton abundance between sampling sites varied on following order, $\mathrm{TA}_{\mathrm{E}}$ $>\mathrm{TA}_{\mathrm{N}}>\mathrm{TA}_{\mathrm{I}}=\mathrm{TA}_{\mathrm{S}}$ (TA refers to total abundance).

Among the physico-chemical parameters tested, only chlorophyll-a showed strong positive correlation with total abundance (Figure 2). One-way ANOVA for chlorophyll-a showed significant difference with location $\mathrm{p}=0.001$ ). Further, Tukey's pair wise comparison showed chlorophyll-a concentration varied among sampling sites in following order, $\left.\left.\left.\mathrm{Ch}_{\mathrm{N}}\right\rangle \mathrm{Ch}_{\mathrm{E}}\right\rangle \mathrm{Ch}_{\mathrm{S}}\right\rangle \mathrm{Ch}_{\mathrm{I}}(\mathrm{Ch}$ refers to chlorophyll-a).

Frequency distributions between plankton composition and species showed that evenness and heterogeneity is very less in north harbor and entrance than south harbor and inner harbor (figure $3,4,5$ and 6$)$. 


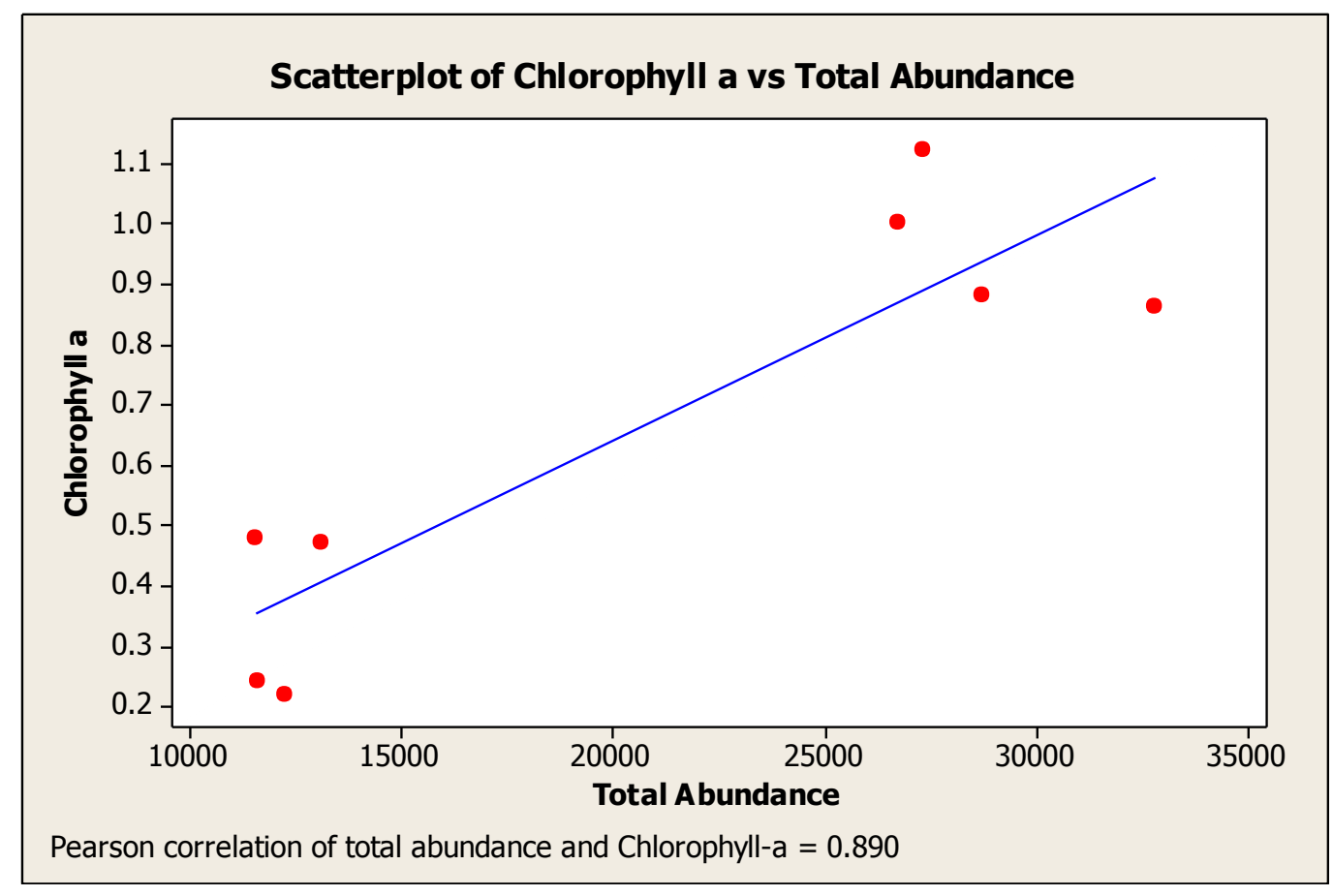

Figure 2: Correlation between chlorophyll-a and total plankton abundance

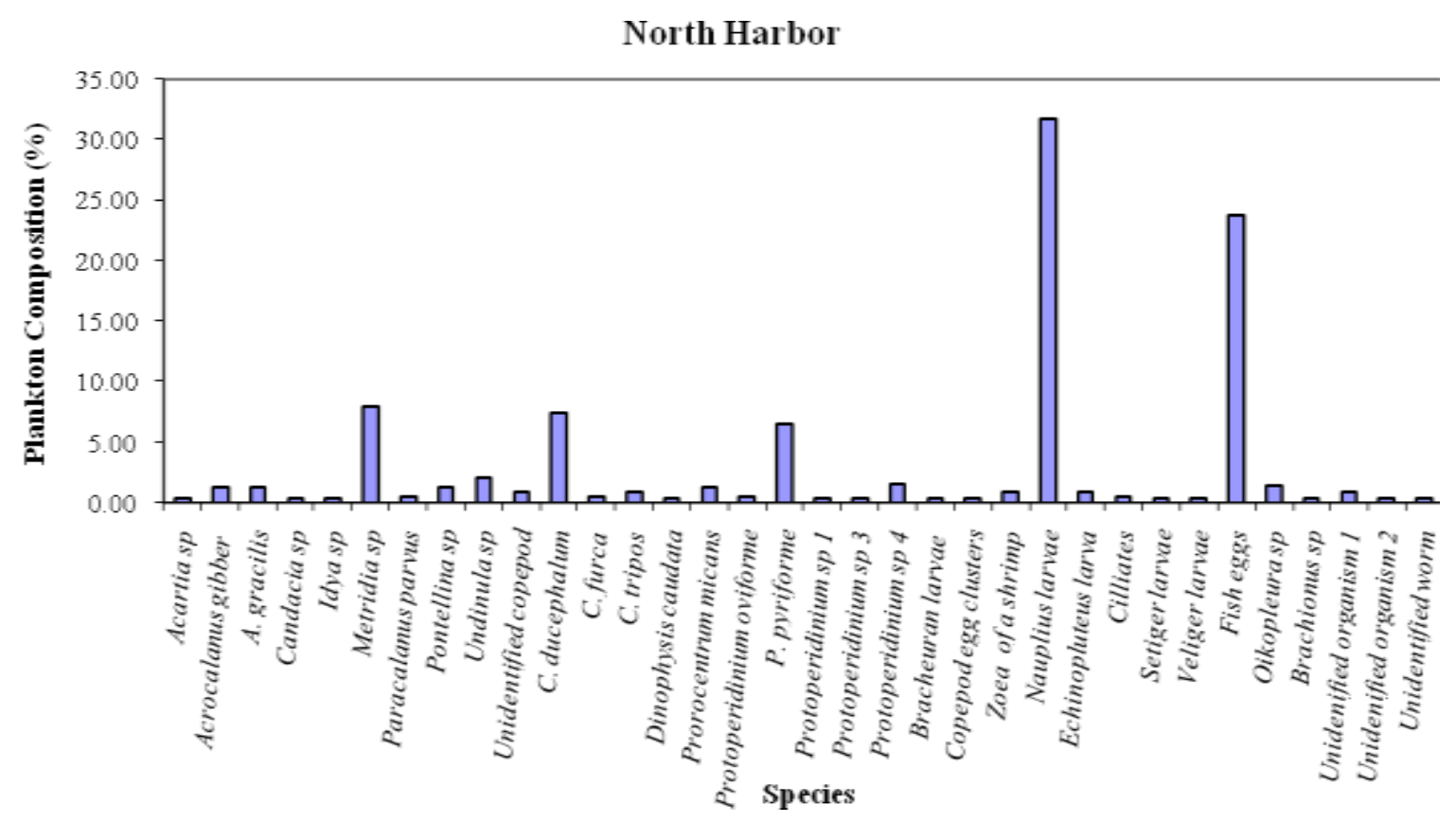

Figure 3: Species Composition in North Harbor 


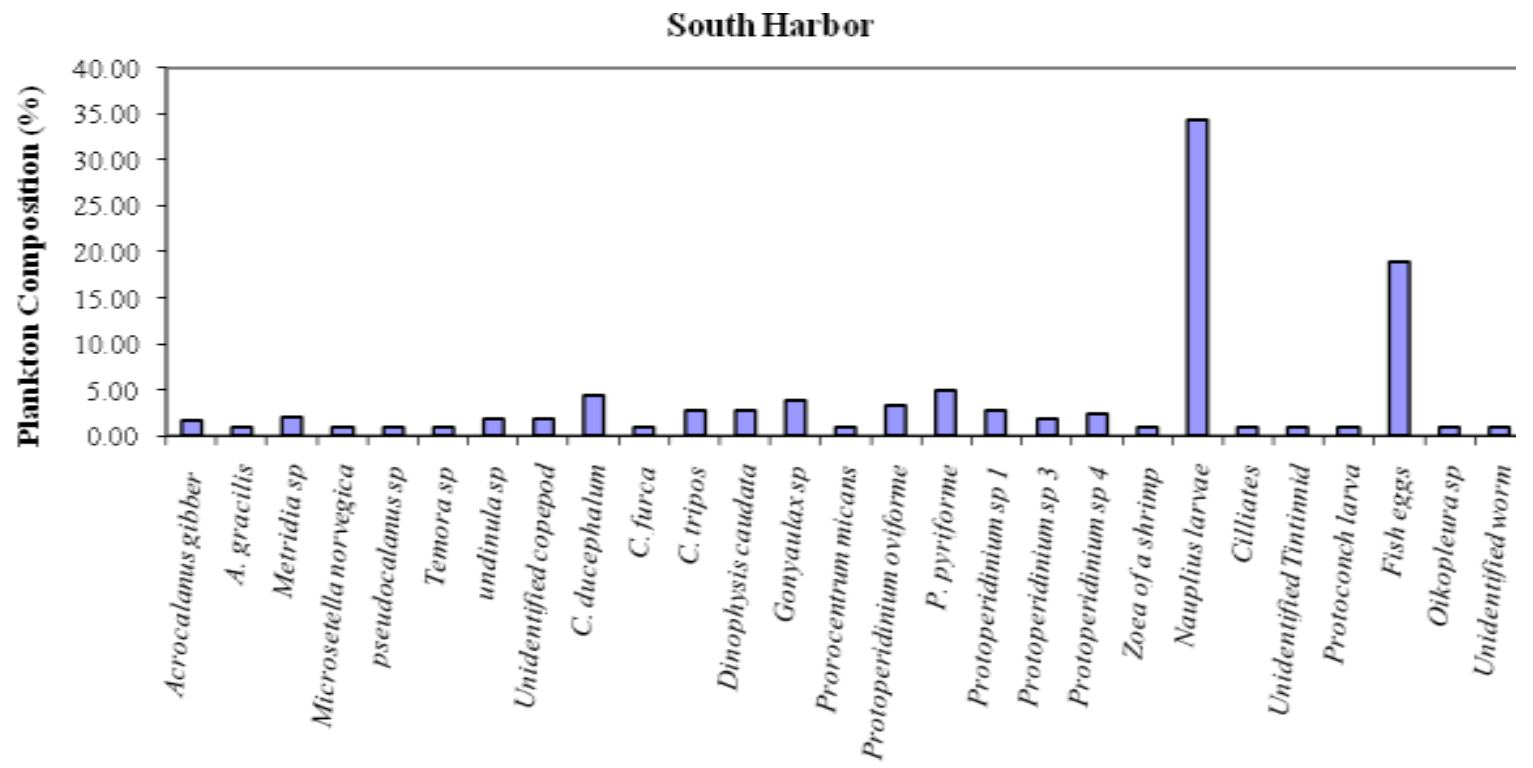

Species

Figure 4: Species Composition in South Harbor

\section{Entrance}

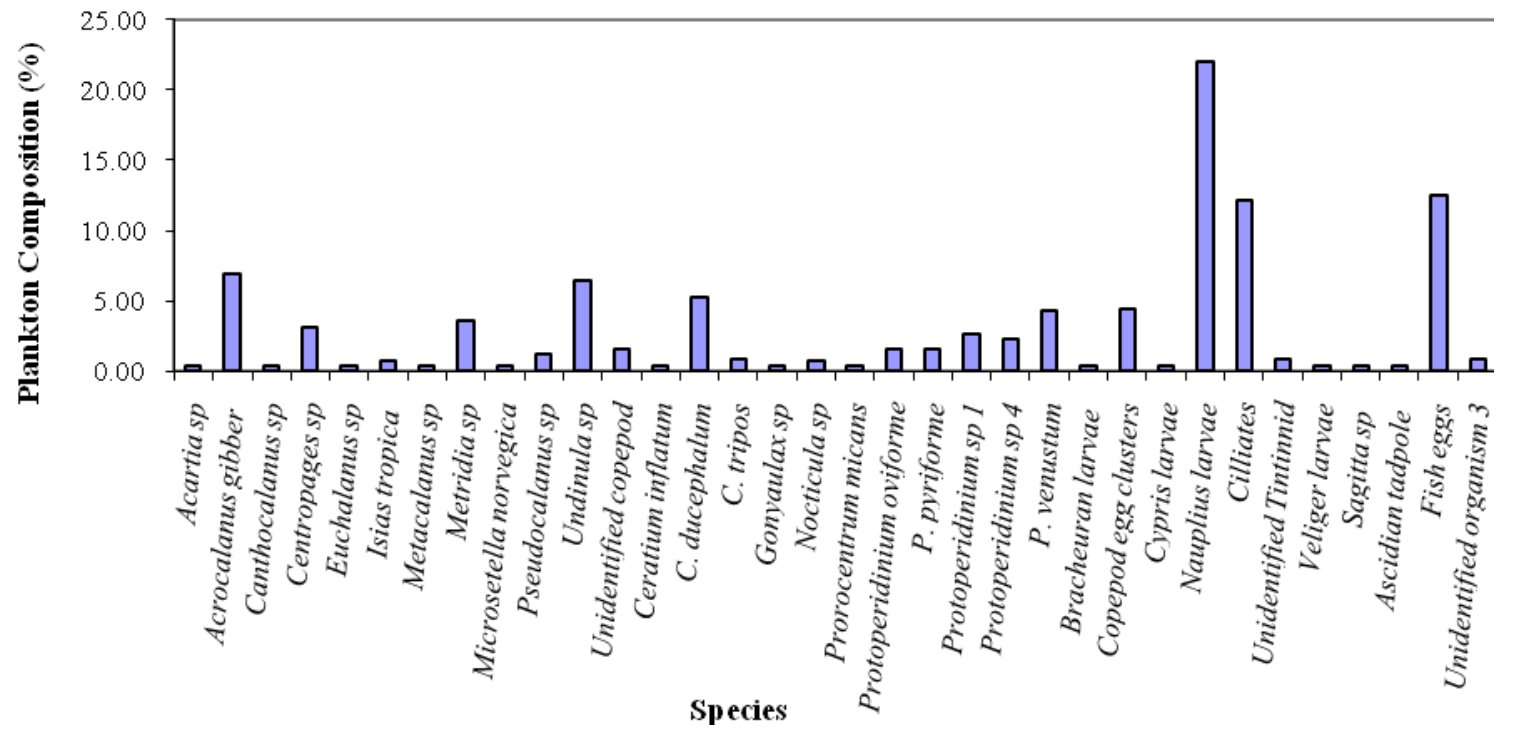

Figure 5: Species Composition in Entrance 


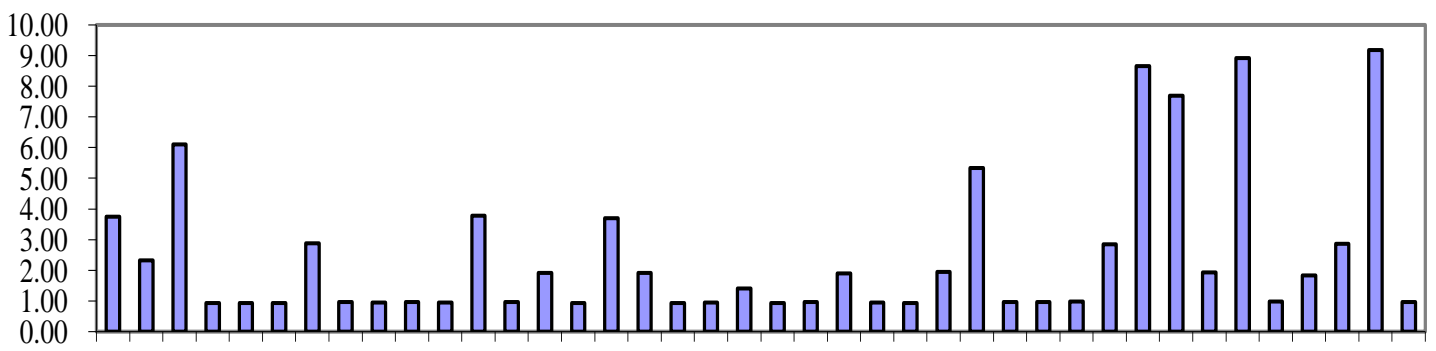

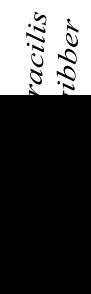

Figure 6: Species Composition in Inner Harbor

\section{DISCUSSION}

Among the four sampling sites, species richness is equal in entrance (E) and north harbor $(\mathrm{N})$, however species evenness and species heterogeneity is very less although highest total abundance of plankton was recorded in these locations. The reasons for the highest abundance in these locations might be high abundance in few species, and the current direction which is directed to north. Since the highest chlorophyll-a concentration recorded from north harbor and entrance, highest total abundance could be observed in these locations since chlorophyll-a play a major role in primary productivity.

Among the 64 species recorded, one species could be identified as brachyuran larva. This brachyuran larva recorded only from entrance and north harbor in composition of $0.37 \%$ and 0.45 $\%$ respectively. In literature brachyuran larva has recorded, in panadura area in with a relative occurrence of $0.1 \%$ (Fernando, 2007). According to Global Invasive Species Program (GISP) Sri Lanka is included in the list of countries that the European Green Crab (Carcinus maenus) which is indigenous to the Atlantic coast of Europe and North Africa can be seen. Considering this factor it is important to carry out a further investigstionto ensure the presence of the European Green crab in Sri Lankan coastal waters.

In the present study there were 9 copepods, 10 Dinoflagellates and 1 foraminiferan, larvae of a barnacle, fish eggs, copepod egg clusters, veliger larvae, ciliates and unidentified worm recorded in inner harbor which were not recorded in inner harbor in previous study(Fernando,2007). Since these 26 species not recorded in previous study they can be considered as alien species introduced to the Colombo harbor via ship's ballast water. Among these 26 species there are two species which also can be seen in ship's ballast water namely, Microsetella $s p$ and Prorocentrum $s p$ (Senanayaka, 2010). Therefore, further studies should be carried out frequently to monitor any change in species composition since ships arriving at Colombo harbor is increasing annually. 


\section{ACKNOWLEDGEMENT}

We should convey our gratitude to Marine Environmental protection Authority (MEPA), Sri Lanka Ports Authority (SLPA), and Sri Lanka Navy for the assistance given thorough out the study.

\section{REFERENCES}

Botes, L., 2003, Phytoplankton identification catalogue- Saldanha Bay, South Africa, April 2001, Globallast Monograph Series No.7, IMO London.

Fernando M A S., 2007, A preliminary study on the invasion of plankton species into Colombo harbor, through the disposal of ballast water, BSc (Hons) thesis, Department of Zoology, University of Kelaniya.

Grasshoff et al., 1999, Methods of Sea water analysis, Wiley-VCH, Third ed., p77 - p172.

Gross, M. G. \& Gross, E., 1996, Oceanography; A view of earth, prentice hall.Inc, $7^{\text {th }}$ edition, p 420.

Jayasiri, H. B., 2009, A guide to the marine plankton gulf of Mannar \&Palk Strait, Sri Lanka, National Aquatic Resources Research and Development Agency.

Kasturirangan, L. R., 1963, A key for the identification of the more common planktonic copepod of Indian Coastal waters, Indian National Committee on Oceanic research.

Lanka Hydraulic Institute, 2009, Sri Lanka: Assessing Colombo Municipality Wastewater Systems, p-10.

Perry, R., 2003, A Guide to the marine plankton of southern California, UCLA Ocean globe [online], 3rd edition. Available at: http://www.msc.ucla.edu/Oceanglobe [Accessed on: 10/06/2010].

Poorter, M. D., 2009, Marine Menace: Alien invasive species in the marine environment,IUCN [online] Available at: http://www.cbd.int/invasive/doc/marine-menace-iucn-en.pdf [Accessed on: 10/06/2010].

Robin, R. S. \& Patra, S., 2009, Manual methods for measuring nutrients, Manual: Training workshop on Marine Resources sampling, Data collection \& interpretation for the South Asian Seas; South Asia Cooperative Environment programme (SACEP), Sri Lanka, p79.

Streftaris, N. and Zenetos, A., 2006, Alien Marine Species in the Mediterranean and their Impact [online]. Available at: http://www.medit-mar-sc.net/files/200812/15-1753359.pdf [Accessed on: 10/06/2010]. 